\section{Treatment of Hypoadrenalism}

Sir,-Sir Derrick Dunlop (October 12 , p. 887) and the writer of your leading article in the same issue (p. 882) both recommend cortisone acetate plus fludrocortisone as adequate treatment for patients suffering from Addison's disease and for those whose adrenal glands have been removed surgically.

The human adrenal cortex secretes hydrocortisone (cortisol) and not cortisone. The latter is biologically inactive. Cortisone is used as replacement therapy because it is easier and therefore cheaper to manufacture and is normally effective because it is converted to hydrocortisone in its passage through the liver. Under certain circumstances-namely, liver disease - the conversion of cortisone to hydrocortisone is impaired and satisfactory replacement is not obtained with the recommended dose of cortisone (25$37.5 \mathrm{mg}$.) nor with amounts up to $75 \mathrm{mg}$ daily. The administration of tablets of hydrocortisone $20 \mathrm{mg}$. in the early morning and $10 \mathrm{mg}$. at mid-day, simulating the normal diurnal rhythm of hydrocortisone secretion, will be noted by these patients to be accompanied by a greatly increased feeling of well-being. Three of our patients adrenalectomized for Cushing's syndrome, who were requiring $75 \mathrm{mg}$. of cortisone acetate daily, plus 0.1 or 0.2 mg. of fludrocortisone, and who did not feel well on this dose, were found to have moderately increased retention of bromsulphthalein (B.S.P.) at $\mathbf{4 5}$ minutes. They were greatly improved by transfer to $30 \mathrm{mg}$. of hydrocortisone. Others with normal B.S.P. tests whose treatment was altered from cortisone to hydrocortisone without them being told have remarked spontaneously about how well they were now feeling.

Despite its slightly higher cost it would seem that hydrocortisone B.P. is to be preferred to cortisone acetate as the natural glucocorticoid replacement therapy in patients with loss of adrenal function. Fludrocortisone is also given in a dose of $0.1 \mathrm{mg}$. to replace aldosterone.-I am, etc.,

E. J. Ross.

University College Hospital Medical School,

London W.C.1.

\section{Addiction to Amphetamines}

SIR,-It is a sad reflection on our corporate responsibilities as physicians that at this time Miss M. C. Paterson (September 14, p. 684) should find it necessary to express the continued and growing anxiety of workers in the many fields regarding the extent of habituation to amphetamines. The matter has indeed been investigated and received serious consideration ranging from Connell's ${ }^{1}$ description of amphetamine psychosis to your recent leading article (August 17, p. 399), yet the problem continues to grow.

In a survey conducted by general practitioners ${ }^{2}$ nearly one in five of those receiving these drugs were shown to be habituated, and those at greatest risk appeared to be the very patients for whom amphetamines are most commonly prescribed. Apart from the doubtful therapeutic necessity for these drugs there appears at times to be a carelessness in their prescription which amounts to real negligence.

If we are to avoid the ogre of ministerial direction we must accept full responsibility for our prescribing habits. How long is it since most of us were faced with a case of morphine addiction ?-the rarity of the condition is not due to any lack of addictive properties but to the responsibility which is usually exercised in prescribing the drug.

The amphetamines deserve equal respect, and until they receive it the courts rather than physicians will exercise control.-I am, etc.,

\section{Department of Psychiatry Columbia University College of Physicians and Surgeons. \\ REFERENCES \\ 1 Connell, P. H., Amphetamine Psychosis, 1958 Maudsley Monographs, No. 5. Chapman and Hall, London. \\ 2 Brandon, S., and Smith, D., J. Coll. gen. Practit. 1962, 5, 603 .}

\section{Toxicity of Acetazolamide}

SIR,-Your article on anticonvulsants (October 12, p. 919) in the "To-day's Drugs" series was a welcome review of an important topic, which will have been widely read. The statement made in that article that major toxic effects have not been observed with acetazolamide should not go unchallenged. Mention should be made of the renal complications of treatment with this drug, which is also used as a long-term measure in glaucoma and even heart failure.

The substance is chemically a heterocyclic sulphonamide. Crystals, resembling those obtained by recrystallization of acetazolamide in acid solution, have been demonstrated at necropsy in the renal tubules of a man treated with the drug 24 days earlier. ${ }^{2}$ Gill and Vermeulen, discussing a possible association between urolithiasis and treatment with " diamox" (acetazolamide), reviewed reported cases and designed animal experiments to test it. They reported marked crystalluria in rats given acetazolamide, but were only able to induce renal calculus formation when in addition the urinary tract was subjected to operative insult or a foreign body was placed in the bladder.

Becker and Middleton," Scheie," and Persky et al." all reported renal complications associated with acetazolamide therapy. Barraquer and Escribano described typical renal colic in 30 patients among 300 with glaucoma treated in this way. In this country Yates-Bell ${ }^{\prime}$ published a case with bilateral non-calculous ureteric obstruction attributed to the drug, relieved by ureteric catheterization. He also discussed a similar patient, who died with anuria, reported by Dr. L. H. Worth at the Royal Society of Medicine on February 28 , 1956, but not published. Davies described two patients, one of whom had repeated episodes of renal colic closely related to administration of the drug. This man, who had unilateral suppression of urine on one of these occasions, was relieved by ureteric catheterization. Although these complications of treatment may be infrequent. they need to be recognized as such not only because they can be serious but also to prevent continued administration of the offending agent.-I am, etc.,

\section{Wynne Davies.}

Barnt Green, Worcs.

REFERENCES

Glushien, A. S., and Fisher, E. R., J. Amer. med. Ass. 1956, 160,204

med. Ass. 1956, 160, 204. $C$ W. $1962,88,103$.

Becker. B. and Middleton, W. $\mathbf{H}$, Ophthal., 1955, 54, 187.

Scheie, H. G., Amer. J. Ophthal 1955, 39, 887. Persky, L.. Chambers, D. and Potts, A. 887. Amer. med. Ass., 1956, 161, 1625.

- Barraquer, J., and Escribano, J., Rev. clin. esp. $1957,64,310$.

Yates-Bell, J. G., Brit. med. J., 1958, 2, 1392.

- Davies, D. W., ibid., 1959, 1. 214.

\section{Urethral Diverticula in Women}

Sir,-Dr. Anthony Phillips, commenting on his interesting case of diverticulum of the female urethra containing multiple calculi (October 12, p. 917), says that it would appear likely that this lesion is acquired and not congenital, because 80 to $90 \%$ of the reported cases occurred in parous women.

Of the three possible causes of urethral diverticulum-infection, trauma, and congenital abnormality-infection has in the past been considered by many authors to be the most likely. However, there is usually no history of a previous parurethral abscess even when the sac of the diverticulum is large, and, although the female urethra is frequently infected on account of its complicated glandular structure and its exposed position, diverticula are relatively rare.

Trauma resulting from difficult childbirth, urethral instrumentation, or passage of a calculus have been suggested as possible aetiological factors, ${ }^{1}$ but there is seldom any. history of direct trauma apart from child-bearing, and this condition is much more likely to cause dislocation of the urethra from behind the symphysis pubis than the characteristic sac of a urethral diverticulum with its narrow neck, muscular wall, and epithelial lining.

The third possibility, that the diverticulum is due to a congenital abnormality, seems to fit the available facts best. Diverticula are situated behind the middle third of the urethra near the insertion of the pubo-coccygeus in a remarkably constant manner. ${ }^{2}$ The sac is sometimes lined by squamous or columnar epithelium which can hardly have come secondarily from the urethral transitional epithelium. Also, those occasional specimens which are seen in very young children, ${ }^{3}$ or into which an ectopic ureter opens, can only be congenital in origin.

It is likely, therefore, that diverticula of the female urethra, like those of the bladder and colon, are congenital in 
origin and symptomless unless they become accidentally infected or very large. Symptoms arising in a previously quiescent diverticulum as a result of infection due to trauma, either from catheterization or the passage of the foetal head, would explain the high incidence of parous women in the series so far recorded.

Urethral diverticula, while apparently not so common in Great Britain as in some parts of the United States of America and the West Indies, are by no means very rare. I have personally encountered two in London in the past four years, and Mr. Geoffrey Dixon has recently drawn my attention to a third example which, like Dr. Phillips's case, contained calculi.

It is likely that if looked for carefully by British gynaecologists and urologists urethral diverticula would be found more often. This has certainly been the case elsewhere.-I am, etc.,

J. H. M. Pinkerton.

Department of Midwifery and

Gynaecology,
The Queen's University of Belfast.

REFERENCES

1 Downer, I. G., and Virgilio, F. D., J. Urol., 1945, 54, 53.

2 Pinkerton, J. H. M., J. Obstet. Gynaec. Brit. Emp.. 1956, 63, 76

3 McMahon, S., J. Urol., 1946, 55, 69.

\section{Antibiotic Cover for Dental Extractions}

SiR,-In the clinicopathological conference on valvular disease of the heart (August 31, p. 545) Dr. J. F. Goodwin stated that he had not seen subacute bacterial endocarditis from Streptococcus viridans develop after dental extractions in which antibiotic cover had been used. For this reason we should like to record the following case.

A primigravida aged 27 was seen in the second trimester of pregnancy and a diagnosis of severe rheumatic mitral stenosis and incompetence and severe aortic incompetence with cardiomegaly was made. She gave a past history of probable subacute bacterial endocarditis in other hospitals on three occasions. She had a non-toxic goitre and dental sepsis, and in view of the latter was referred for dental surgery. Extraction was advised and was carried out under a penicillin umbrella. The patient received $6,000,000$ units of crystalline penicillin; the first dose of $1,000,000$ units was given approximately one hour before the extraction, two further doses of $1,000,000$ units were given on the day of extraction, two on the day following, and a final 1,000,000 units on the morning of the second post-operative day. In addition she was given penicillin $V$, $250 \mathrm{mg}$. three times a day for four days, starting on the day of extraction. Two weeks later she was admitted to hospital complaining of pain in the loin and the abdomen, and frequency. Her temperature was $97^{\circ} \mathrm{F} .\left(36.1^{\circ} \mathrm{C}\right.$. $)$ and there were no stigmata of subacute bacterial endocarditis. For some days previously she had had a swinging fever up to $102^{\circ} \mathrm{F}$. $\left(38.9^{\circ} \mathrm{C}\right.$.) and had been treated by her practitioner with "terramycin" (axytetracycline) and "furadantin" (nitrofurantoin) for four days for presumed pyelitis of pregnancy. Furadantin $100 \mathrm{mg}$. four times a day was given for a further three days. Five days after all antibiotic treatment was discontinued her temperature rose to $102^{\circ} \mathrm{F}$. $\left(38.9^{\circ} \mathrm{C}\right.$. $)$. Blood culture showed Streptococcus viridans sensitive to penicillin, "achromycin" (tetracycline), "chloromycetin" (chloramphenicol), terramycin, and streptomycin. She was treated with crystalline penicillin $(2,000,000$ units eight-hourly) for six weeks. On cessation of treatment she remained afebrile and blood culture was sterile. Spontaneous vaginal delivery of a living male child was made under penicillin cover at term. The puerperium was uncomplicated.

It seems likely that the streptococcal septicaemia in this case was related to the dental extraction, and at the time of the positive blood culture subacute bacterial endocarditis was actual or imminent. The patient had appeared ill within a few days of discontinuation of antibiotic prophylaxis and had been treated with terramycin for presumed pyelitis of pregnancy. Examination of the urine subsequent to her admission to hospital, though repeated, showed no evidence of urinary tract sepsis, although red blood cells were seen on one occasion. It seems therefore that streptococcal septicaemia persisted in spite of attempted prophylaxis with penicillin. The organism recovered from the blood-stream was sensitive to penicillin, and the patient recovered after prolonged treatment with penicillin. We are at a loss to explain the apparent failure of prophylaxis in this case.-We are, etc..

\section{G. BARNES Rosalinde Hurley.}

Queen Charlotte's Maternity Hospital,

London W.6.

\section{Nicotine and Colonic Muscle}

SIR.--In the interesting preliminary communication published in your journal on the above-mentioned subject (September 14. p. 666) it was observed by $\mathrm{Dr}$. D. J. Fishlock and Mr. A. G. Parks that nicotine did not cause stimulation of the human colonic muscle, in vitro, in any dose range. In their experiments the studies were made on the strips of colon obtained from patients under anaesthesia, and it is likely that these subjects were atropinized. On rabbit colon nicotine has been shown to cause stimulation which is abolished by atropine. ${ }^{1}$

It is probable that on human colon also the initial pre-anaesthetic atropine may have been given which would block the muscarinic effect of nicotine. It would be interesting to know the type of premedication given to these patients. If atropine was in fact given, were the reported responses to acetylcholine quantitatively in a correct range. or were these due to excess acetylcholine overcoming the block?-We are, etc.,

\section{K. C. DAVE.}

K. S. SACHDEv.

\section{Denartment of Pharmacology.} Jamnagar, India.

REFERENCE

1 Gillesnie, J. S., and Markenna. B. R., J. Physiol. (Lond.), 1960, 152, 191
Pigmentation and Vitamin-B $B_{12}$ Deficiency

SIR,-Our attention has just been drawn to an excellent article published in 1944 by Dr. Bramwell Cook entitled "A Vitamin B Deficiency Syndrome Allied to Sprue "' in which he gives a beautiful description of the type of pigmentation described in our article of June 29 last (p. 1713). He says, "The skin overlying the knuckles of the fingers looks darker than normal, and his complexion is sallow and muddy. There may be darkness of the skin around the neck and the lips. The patient is conscious and concerned about his blackness. ..." And again, "The common sites of pigmentation are: on the knuckles, the tongue (black spots may appear on the dorsum of the tongue), around the lips and in the nasolabial folds, on the forehead, under the eyes, on the dorsum of the ankles, back of the wrist, extensor surface of the arms, front of the neck, front of the legs below the knees."

Dr. Cook also observed that this pigmentation was associated with a macrocytic anaemia, and that both it and the anaemia responded to crude liver extract.

As far as we are aware this is the first documented description of this type of pigmentation which we now know to be associated with vitamin- $B_{12}$ deficiency.

-We are, etc.,

S. J. BAKER.

MerCy IgNatius.

S. JOHNSON.

S. K. Vaish.

\section{Wellcome Research Unit, Christian Medical College.
Vellore, South India.}

REFERENCE

Conk, B. A., Indlan med. Gaz.. 1944, 79, 429

\section{Toxic Reactions to Drugs}

SiR,- - The Subcommittee on Adverse Reactions of the Committee on Safety of Drugs intends to form a central register of toxic reactions to drugs both old and new and will shortly be issuing forms for the notifications of such reactions. One of the main tasks of the committee will be to assess the incidence of reactions in relation to the frequency of prescription of the drugs concerned. We therefore hope to make the central register as complete and as accurate as possible. We shall be grateful if any groups of workers or societies in the United Kingdom who are already keeping a register of adverse reactions or are contemplating doing so will get in touch with the Subcommittee on Adverse $\mathrm{Re}$ actions so that information can be exchanged and duplication avoided. Communications should be addressed to the Medical Secretary, Committee on Safety of Drugs, 1 Alexander Fleming House, Elephant and Castle, London S.E.1.-I am, etc.,

L. J. WITTS,
Chairman,
Subcommittee on Adverse Reactions,
The Radcliffe Infirmary,
Oxford.
The Radcliffe Infirmary 